\title{
SILAGEM ÁCIDA DE RESÍDUOS DA FILETAGEM DE TILÁPIAS PARA GIRINOS DE RÃ-TOURO (Rana catesbeiana Shaw,1802) - DIGESTIBILIDADE E DESEMPENHO
}

\author{
Acid silage of filetage from tilapia residues for frog-bull tadpoles \\ (Rana catesbeiana Shaw,1802) - (Digestibility and performance assays)
}

\author{
Marinez Moraes de Oliveira1, Maria Emília de Sousa Gomes Pimenta², Antônio Cleber da Silva Camargo ${ }^{3}$, \\ Carlos José Pimenta ${ }^{4}$, Priscila Vieira Rosa Logato ${ }^{5}$
}

\begin{abstract}
RESUMO
Os experimentos foram realizados para avaliar os coeficientes de digestibilidade aparente dos nutrientes e da energia bruta da silagem ácida de resíduos da filetagem de tilápia do Nilo (Oreochromis niloticus), para girinos de rã - touro (Rana catesbeiana) e o desempenho dos girinos recebendo níveis crescentes $(0,15,30 \%)$ da silagem ácida em substituição à farinha de peixe na ração. Na digestibilidade foram utlizados 200 girinos, medindo em média $7 \mathrm{~cm}$ e peso médio de $3 \mathrm{~g}$, acondicionados em aquários de 40 litros. A coleta de fezes foi feita em 7 dias e a determinação dos coeficientes de digestibilidade aparentes e energia digestível aparente foi feita por metodologia indireta, tendo sido utilizado $1,0 \%$ de $\mathrm{Cr}_{2} \mathrm{O}_{3}$ como indicador incorporado à ração. No desempenho foram utilizados 240 girinos, com peso médio de $2,5 \mathrm{~g}$ acondicionados em aquários de 40 litros. As variáveis analisadas foram: ganho de peso final (GPF); consumo de ração total (CRT); e conversão alimentar aparente (CAA). O delineamento utilizado foi o inteiramente casualizado, com 3 tratamentos e 16 repetições. Os valores de digestibilidade encontrados foram: coeficiente de digestibilidade aparente da matéria seca 95,48; coeficiente de digestibilidade aparente da proteína bruta 95,90; coeficiente de digestibilidade aparente do extrato etéreo 99,25; coeficiente de digestibilidade aparente da energia bruta 95,75 e o coeficiente da energia digestível aparente $(\mathrm{kcal} / \mathrm{kg}) 2418,04$. Observou-se uma diminuição linearmente $(\mathrm{P}<0,01)$ para o ganho de peso final e consumo de ração total. Concluiu-se que este alimento prejudicou o desempenho, apesar dos altos coeficientes de digestibilidade.
\end{abstract}

Termos para indexação: Girinos, digestibilidade, desempenho, filetagem de tilápia, silagem ácida.

\begin{abstract}
The experiments were conduct in order to evaluate the nutrients apparent digestibility coefficients and gross energy and performance assay by using the acid silage from tilapia filetage residues of Nile's tilapia (Oreochromis niloticus) for frog - bull tadpoles (Rana catesbeiana) using increasing levels $(0,15,30 \%)$ of acid silage residues in substitution to the fish meal in the ration of frog - bull tadpoles. For the digestibility assay were utilized 200 tadpoles, measuring on an average $7 \mathrm{~cm}$, packed in aquaria of 40 liters. The feces collection was made in 7 days and the coefficients apparent digestibility of nutrients and energy digestible determination were made by indirect methodology and using 1,0\% of $\mathrm{Cr} 2 \mathrm{O} 3$ as diet indicator. In the performance assay a total of 240 tadpoles were utilized, with middleweight of $2,5 \mathrm{~g}$ packed in aquaria of 40 liters. The variables analyzed were: weight gain (WG); total feed intake (TFI); and apparent feed conversion (AFC). The experimental was in the entirely randomized design, with 3 treatments and 16 repetitions. The digestibility values were: Apparent coefficient of Dry Matter 95.48; Apparent coefficient of crude protein 95.90; Apparent coefficient of ethereal extract 99.25; Apparent crude energy digestibility coefficient 95.75 and digestible energy ( $\mathrm{kcal} \mathrm{DE} / \mathrm{kg})$ 2418. The results shown linearly decreased $(\mathrm{P}<0,01)$ for the weight gain and feed intake. It was conclude that the acid silage from tilapia filetage residues shown low performance, therefore high nutrients digestibility of diets for bull tadpoles (Rana catesbeiana).
\end{abstract}

Index terms: Tadpoles, digestibility, performance, filetage of tilapia, silage acid.

(Recebido em 19 de abril de 2005 e aprovado em 27 de setembro de 2006)

\section{INTRODUÇÃO}

A exploração comercial da criação de rãs em cativeiro é baseada, praticamente em sua totalidade, na exploração de rã - touro (Rana catesbeiana) originária da
América do Norte, a qual apresenta ótima adaptabilidade produtiva e reprodutiva em climas tropicais e subtropicais. As principais modificações que ocorreram na ranicultura, com relação à alimentação, surgiram a partir da década de 80. Entretanto, a falta de conhecimento de

\footnotetext{
${ }^{1}$ Mestre em Ciência Animal, Bolsista de DTI da Universidade Federal de Lavras/UFLA - Cx. P. 3037 - 37200-000 - Lavras, MG-marinez.moraes@ig.com.br ${ }^{2}$ Doutora em Nutrição de Monogástrico, Pesquisadora da EPAMIG - Fazenda Experimental Leopoldina - Cx. P. 47 - $36700-000$ - Leopoldina, MG me.pimenta@epamig.br

${ }^{3}$ Doutor em Zootecnia, Professor - Universidade Federal de Minas Gerais/UFMG - Cx. P. 135 - $39404-006$ - Montes Claros, MG antoniobebo@hotmail.com

${ }^{4}$ Doutor em Ciência dos Alimentos - Universidade Federal de Lavras/UFLA - Cx.P. 3037 - 37200-000 - Lavras, MG - carlos_pimenta@ufla.br

${ }^{5}$ Doutora em Piscicultura - Universidade Federal de Lavras/UFLA - Cx. P. 3037 - 37200-000 - Lavras, MG - priscila@ufla.br
} 
suas exigências nutricionais, a qualidade dos alimentos e manejo alimentar, ainda constituem fatores limitantes para o maior desenvolvimento da ranicultura brasileira. A fase de girinos é uma etapa fundamental para o bom andamento de qualquer ranário. Muitas vezes há ocorrência de desenvolvimento anormal ou mortalidade, apresentando sinais prováveis de deficiências nutricionais (VEIGA, 1989).

Durante a fase de crescimento os girinos têm comportamento alimentar generalista, consumindo todo tipo de resíduos vegetais e animais e até mesmo as próprias fezes. Em sistemas intensivos de criação, no qual os girinos dependem diretamente da oferta de alimento balanceado, é essencial que este esteja disponível em quantidade e qualidade adequadas.

As rações utilizadas na alimentação de girinos e de peixes têm como principal fonte de proteína de origem animal a farinha de peixe, a qual normalmente tem apresentado baixa qualidade nutricional, com produção sazonal e alto custo, elevando, portanto, o custo de produção para o ranicultor.

De acordo com Lima \& Agostinho (1992), o custo com alimentação de rãs representa $57,1 \%$ do custo total da criação.

Vários estudos têm investigado a possibilidade do uso de ingredientes alternativos em substituição à farinha de peixe em dietas de organismos aquáticos, tais como a silagem de peixe produzida a partir de resíduos da filetagem de tilápias e também do descarte de peixes inteiros (CISSE et al., 1995; ESPE et al., 1999; RAMOS et al., 1994).

Portanto, uma alternativa para o aproveitamento de resíduos da indústria pesqueira, na elaboração de dietas para organismos aquáticos, é o ensilado de pescado, produto que possui alto valor biológico e, praticamente, a mesma composição da matéria-prima que o origina (WINDSOR \& BARLOW, 1984).

Considerando a importância de se conhecer os diversos aspectos da alimentação para girinos de rã, dentre eles viabilizar a utilização de alimentos alternativos, o presente trabalho teve por objetivo verificar a digestibilidade da silagem ácida de resíduos da filetagem de tilápias e avaliar o desempenho de girinos de rã-touro submetidos a diferentes níveis de inclusão desse ingrediente em substituição à farinha de peixe na ração.

\section{MATERIAL E MÉTODOS}

\section{Digestibilidade}

O ensaio foi conduzido no Laboratório de Reprodução de Peixes da Universidade José do Rosário Vellano, UNIFENAS, em Alfenas - MG, no período de julho a agosto de 2004, objetivando avaliar o coeficiente de digestibilidade aparente (CDA) da matéria seca, proteína bruta e do extrato etéreo da silagem ácida de resíduos da filetagem de tilápia, para posterior balanceamento de uma ração para girinos de rã - touro (Rana catesbeiana).

Foram utilizados 200 animais, distribuídos em 10 aquários inclinados com capacidade para 40 litros de água. A determinação do coeficiente de digestibilidade aparente e energia metabolizável aparente foi realizada pelo método indireto, sendo utilizado como indicador $1,0 \%$ de óxido de cromo $\left(\mathrm{Cr}_{2} \mathrm{O}_{3}\right)$ incorporado à ração, conforme metodologia descrita por Cho (1987) e Cho et al. (1985).

A dieta foi elaborada utilizando uma ração prática como referência, sendo esta composta por $70 \%$ da ração referência $+30 \%$ do ingrediente a ser testado segundo tabela de exigências para peixes (NRC,1993).

Os girinos de rã - touro (Rana catesbeiana) originaram-se do setor de Ranicultura da Universidade José do Rosário, Alfenas - MG, medindo em média $7 \mathrm{~cm}$ e com peso médio de $3 \mathrm{~g}$.

Os tratamentos foram sorteados para o início da fase pré-experimental, sendo que os girinos de 5 aquários (cada aquário continha 20 girinos) receberam ração referência e girinos dos 5 aquários restantes (contendo também 20 girinos cada) receberam $70 \%$ da ração referência $+30 \%$ do ingrediente teste. A composição da ração referência encontra-se na Tabela 1 .

Os girinos receberam as dietas experimentais durante os três primeiros dias, denominado período préexperimental. O período experimental teve a duração de 7 dias com a coleta de fezes em todos eles.

A coleta de fezes foi feita 3 vezes ao dia: às 7:30 horas, 11:30 horas e 15:30 horas, através de mangueira acoplada ao fundo do aquário e que o interliga ao coletor de fezes. A alimentação dos girinos foi feita logo após a coleta de fezes, às 8:30 h, 12: $30 \mathrm{~h}$ e às 16:30 horas.

Após 30 minutos da última refeição, todos os aquários foram sifonados com uma mangueira acoplada no fundo dos respectivos aquários, visando a eliminação dos restos da ração, fezes e resíduos; $70 \%$ da água era retirada para limpeza dos mesmos.

Toda a água era então drenada para a limpeza interna, ficando o sistema preparado para a coleta de fezes na manhã do dia seguinte.

As fezes livres caracterizaram-se por pequenos grânulos, porém, quando decantadas no coletor de fezes, apresentaram-se amorfas.

Fezes e água foram acondicionadas em vidro, em seguida foram centrifugadas a $4200 \mathrm{rpm} / 8$ minutos a 20 $22^{\circ} \mathrm{C}$, e secas em estufa a $65^{\circ} \mathrm{C}$. Aproximadamente 28 horas após a secagem estas foram maceradas e armazenadas em vidros com tampas, para posteriores análises. 
Tabela 1 - Ração referência utilizada no ensaio de digestibilidade.

\begin{tabular}{lc}
\hline Ingredientes & Quantidade $(\mathrm{kg})$ \\
\hline Milho & 61,00 \\
Farelo de Soja & 30,00 \\
Fosfato Bicálcico & 2,60 \\
Calcário calcítico & 1,60 \\
BHT & 0,20 \\
Aglutinante (Alginato) & 0,20 \\
Sal comum & 0,50 \\
Caulim & 2,40 \\
Suplemento Mineral e & 0,50 \\
vitamínico & \\
Óxido de Crômio & 1,00 \\
\hline Valores calculados: & \\
Proteína bruta (\%) & 30,00 \\
Energia Digestível (kcal/kg) & 3000 \\
Cálcio Total (\%) & 0,74 \\
Fósforo Total (\%) & 0,60 \\
Fósforo Disponível (\%) & 0,60 \\
Extrato etéreo (\%) & 4,60 \\
Fibra Bruta (\%) & 3,76 \\
\hline
\end{tabular}

${ }^{1}$ Suplemento mineral e vitamínico (Supremais) (Min. Vit. Supplement): Vit. A, 1.200.000UI; Vit. $\mathrm{D}_{3}$, 200.000UI; Vit. E. $12.000 \mathrm{mg}$; Vit. $\mathrm{K}_{3}, 2.400 \mathrm{mg}$; Vit. B, $4.800 \mathrm{mg}$; Vit. B, 4.000 mg; Vit. $\mathrm{B}_{12}, 4.800 \mathrm{mg}$; Ác. Fólico (Folic acid), $1.200 \mathrm{mg}$; Ác. Pantotênico (Pantothenic acid) Ca, 12.000 mg; Vit. C, 48.000 mg; Biotina (Biotin), $48 \mathrm{mg}$; Colina (Colin), $65.000 \mathrm{mg}$; Niacina (Niacin), $24.000 \mathrm{mg}$; Fe, $10.000 \mathrm{mg}$; Cu, $6.000 \mathrm{mg}$; Mn, 4.000 $\mathrm{mg}$; Zn,6.000 mg; I, 20mg; Co, $2 \mathrm{mg}$; Se, $20 \mathrm{mg}$.

Ao término do período de coleta, as amostras foram homogeneizadas e submetidas a análises bromatológicas, realizadas no Laboratório de Análises de Alimentos do Departamento de Zootecnia da Universidade Estadual de São Paulo (UNESP), campus Jaboticabal-SP, segundo a AOAC (1990).

As amostras de água para a determinação das análises químicas foram coletadas no início e no final do ensaio onde o pH médio foi de 7,1 e nitrogênio amoniacal médio de $0,115 \mathrm{mg} / \mathrm{L}$, determinadas no Laboratório de recursos hídricos da UNIFENAS. A temperatura média máxima durante o experimento foi $22^{\circ} \mathrm{C}$ e a temperatura média mínima foi de $17^{\circ} \mathrm{C}$.

Os coeficientes de digestibilidade aparente da matéria seca e dos nutrientes, além da energia digestível aparente foram determinados através da metodologia descrita por Cho (1987) e Cho et al. (1985).
As análises para determinação da concentração do cromo, nas fezes e ração teste, foram realizadas no Laboratório do Centro Nacional de Pesquisa de Peixes Tropicais - CEPTA - IBAMA, Pirassununga - SP, determinado por espectrofotometria de absorção atômica, descrita por Kimura \& Miller (1957), para posteriores cálculos do coeficiente de digestibilidade (MUKHOPADHYAY \& RAY, 1997; NRC, 1993).

\section{Desempenho}

O experimento foi realizado nas estruturas da Piscicultura da Universidade José do Rosário Vellano, Alfenas - MG.

Foram utilizados 12 aquários com capacidade de 40 litros de água, com 20 girinos cada, perfazendo um total de 240 girinos, com peso médio de aproximadamente $2,5 \mathrm{~g}$.

O delineamento utilizado utilizado foi o Delineamento Inteiramente Casualizado, com 3 tratamentos (níveis crescentes de silagem de peixe em substituição à farinha de peixe), 4 aquários recebendo os respectivos tratamentos e as repetições foram obtidas dentro desses aquários onde, para obtenção de cada repetição pesou-se os girinos em grupos de 5 , ou seja, cada aquário disponibilizou 4 repetições.

Os girinos de cada aquário foram pesados individualmente e realizado a média de cada aquário, na qual a ração era fornecida duas vezes ao dia (às $9 \mathrm{~h}$ e $15 \mathrm{~h}$ ), conforme o peso da biomassa na proporção de $10 \%$ da mesma, onde a quantidade foi corrigida a cada biometria.

A água foi sifonada todos os dias para manter a qualidade da mesma. A temperatura média máxima foi de $24^{\circ} \mathrm{C}$ e temperatura mínima de $18^{\circ} \mathrm{C}$.

As rações experimentais foram formuladas com níveis crescentes de silagem ácida de resíduos da filetagem de tilápias em substituição a farinha de peixe $(0$, 15 e 30\%), de acordo com as exigências para peixes conforme NRC (1993), sendo as mesmas isocalóricas e isoprotéicas.

A composição percentual das rações experimentais encontra na Tabela 2.

A composição química dos ingredientes que foram utilizados, baseada em tabelas, encontra-se na Tabela 3 .

Para a elaboração das rações experimentais, os alimentos foram processados individualmente em um moinho tipo faca com peneira de $0,5 \mathrm{~mm}$. Após, foram misturados. Para o fornecimento aos girinos, as rações foram desintegradas e peneiradas de modo a apresentarem granulometrias que melhor se adaptem ao tamanho da boca dos animais. 
Tabela 2 - Composição Percentual das Rações Experimentais.

\begin{tabular}{lrrr}
\hline \multicolumn{1}{c}{ Ingredientes } & Nivel de Silagem (\%) & 30 \\
Óleo de Soja & 0 & 15 & 0,050 \\
Farinha de Peixe & 0,510 & 00,000 & 26,600 \\
Milho & 38,000 & 32,300 & 4,000 \\
Farelo de Soja & 4,000 & 4,700 & 57,100 \\
Silagem & 54,000 & 55,500 & 11,400 \\
Inerte & 00,000 & 5,700 & 0,240 \\
Vitcre-peixe & 2,270 & 1,190 & 0,200 \\
Sal Comum & 0,200 & 0,200 & 0,400 \\
BHT & 0,400 & 0,400 & 0,010 \\
Total & 0,010 & 0,010 & 100,00 \\
Composição Calculada: & 100,00 & 100,00 & 48,000 \\
Proteína Bruta & & & 2,418 \\
E.M. (Kcal/Kg) & 48,000 & 48,000 & 2,176 \\
Cálcio & 2,418 & 2,418 & 1,170 \\
Fósforo & 2,113 & 2,028 & 1,208 \\
\hline
\end{tabular}

${ }^{1}$ Suplemento mineral e vitamínico (Supremais) (Min. Vit. Supplement): Vit. A, 1.200.000UI; Vit. $\mathrm{D}_{3}$, 200.000UI; Vit. E. 12.000 mg; Vit. $\mathrm{K}_{3}, 2.400 \mathrm{mg}$; Vit. $\mathrm{B}_{1}, 4.800 \mathrm{mg}$; Vit. $\mathrm{B}_{6}, 4.000 \mathrm{mg}$; Vit. $\mathrm{B}_{12}, 4.800 \mathrm{mg}$; Ác. Fólico (Folic acid), $1.200 \mathrm{mg}$; Ác. Pantotênico (Pantothenic acid) Ca, $12.000 \mathrm{mg}$; Vit. C, $48.000 \mathrm{mg}$; Biotina (Biotin), $48 \mathrm{mg}$; Colina (Colin), $65.000 \mathrm{mg}$; Niacina (Niacin), 24.000 $\mathrm{mg}$; Fe, $10.000 \mathrm{mg}$; Cu, $6.000 \mathrm{mg}$; Mn, $4.000 \mathrm{mg}$; Zn,6.000 mg; I, 20mg; Co, 2 mg; Se, 20 mg.

Tabela 3 - Composição química dos ingredientes das rações experimentais ${ }^{1}$.

\begin{tabular}{lcccr}
\hline Ingrediente & PB $(\%)$ & EM $(\mathrm{Kcal} / \mathrm{Kg})$ & $\mathrm{Ca}(\%)$ & $\mathrm{P}(\%)$ \\
\hline Farelo de Soja & 45 & 2283 & 0,45 & 0,75 \\
Farinha de Peixe & 60 & 2183 & 6,1 & 3 \\
Milho & 9 & 3416 & 0,02 & 0,53 \\
Óleo de Soja & - & 8786 & - & - \\
Silagem & 48 & 2418 & - & - \\
Calcário & - & - & 37 & - \\
Fosf. Bic. & - & - & 22,61 & 17,03 \\
\hline
\end{tabular}

${ }^{1}$ Valores obtidos em análises conduzidas no Laboratório de Nutrição Animal do Departamento de Zootecnia, UFLA, ou de tabelas de exigências para peixes (NRC, 1993).

Os parâmetros da água pH e Nitrogênio Amoniacal $(\mathrm{mg} / \mathrm{L})$ foram medidos no inicio e final do experimento, sendo o pH médio de 6,9 e o nitrogênio amoniacal (N$\mathrm{NH} 3$ ) médio de $0,117 \mathrm{mg} / \mathrm{L}$.

Ao final do período experimental, as variáveis avaliadas foram: ganho de peso diário $(\mathrm{g})$, consumo de ração final $(\mathrm{g})$, conversão alimentar aparente e sobrevivência.

Os dados obtidos ao final do experimento foram submetidos à análise estatística, utilizando os pacotes computacionais SAEG (EUCLIDES, 1983) e SISVAR (FERREIRA, 2000).

O modelo estatístico foi:

$$
\text { yij }=\mu+T i+\text { eij }
$$

em que:

$\mathrm{i}=1,2,3$

$\mathrm{e}_{\mathrm{ij}}=$ erro associado a cada observação. 


\section{RESULTADOS E DISCUSSÃO}

O coeficiente de digestibilidade aparente dos nutrientes e a energia digestível aparente da silagem ácida de resíduos da filetagem de tilápia encontram-se na Tabela 4.

Tabela 4 - Coeficiente de Digestibilidade Aparente dos Nutrientes e Energia Digestível Aparente da Silagem Ácida de Resíduo da Filetagem de Tilápia para Girinos de rãtouro (Rana catesbeian).

\begin{tabular}{lr}
\hline \multicolumn{1}{c}{ Varíaveis } & \multicolumn{1}{c}{ Valor } \\
\hline CDAMS (\%) & 95,48 \\
CDAPB (\%) & 95,90 \\
CDAEE (\%) & 99,25 \\
CDAEB (\%) & 95,75 \\
EDA $(\mathrm{kcal} / \mathrm{Kg})$ & 2418,04 \\
\hline
\end{tabular}

O coeficiente de digestibilidade aparente dos nutrientes da silagem ácida de resíduos da filetagem de tilápia mostraram que a mesma é eficientemente aproveitada pelos girinos, uma vez que todos os valores foram acima de $90 \%$. Infelizmente a literatura disponível é escassa e permite poucas comparações. Pode-se, entretanto, inferir que, provavelmente, esses valores seriam superiores, caso a temperatura média trabalhada fosse maior, pois a mesma estava abaixo da temperatura adequada a uma taxa metabólica ideal.

Com relação à energia digestível aparente verificouse um valor elevado (2418,08 kcal EDA/kg). Trabalhos com rãs na fase inicial encontraram os valores de $2035 \mathrm{kcal} / \mathrm{kg}$ (CASTRO et al., 1998), $2288 \mathrm{kcal} / \mathrm{kg}$ (CASTRO et al., 1998) e $2242 \mathrm{kcal} / \mathrm{kg}$ (BRAGA et al., 1998), trabalhando com a farinha de peixe para rãs na fase inicial. Qualquer associação, entretanto, pode induzir a informações errôneas, uma vez que esses autores trabalharam com base na energia metabolizável, além de o hábito alimentar nas diferentes fases ser diferente.

Trabalhando com girinos de rã-touro, Albinati (1995) determinou que os valores dos coeficientes de digestibilidade da matéria seca (MS), proteína bruta (PB) e energia bruta (EB) da farinha de peixe foram, 70,56\%, 86,77\% e $78,96 \%$, inferior aos encontrados no presente estudo, o que leva a supor um melhor aproveitamento da silagem quando comparada à farinha de peixe.

O ganho de peso final, o consumo final de ração e a conversão alimentar aparente das rãs que receberam diferentes níveis de silagem ácida de resíduo da filetagem da tilápia (Oreochromis niloticus) encontra-se, respectivamente nas Figuras 1, 2 e 3.

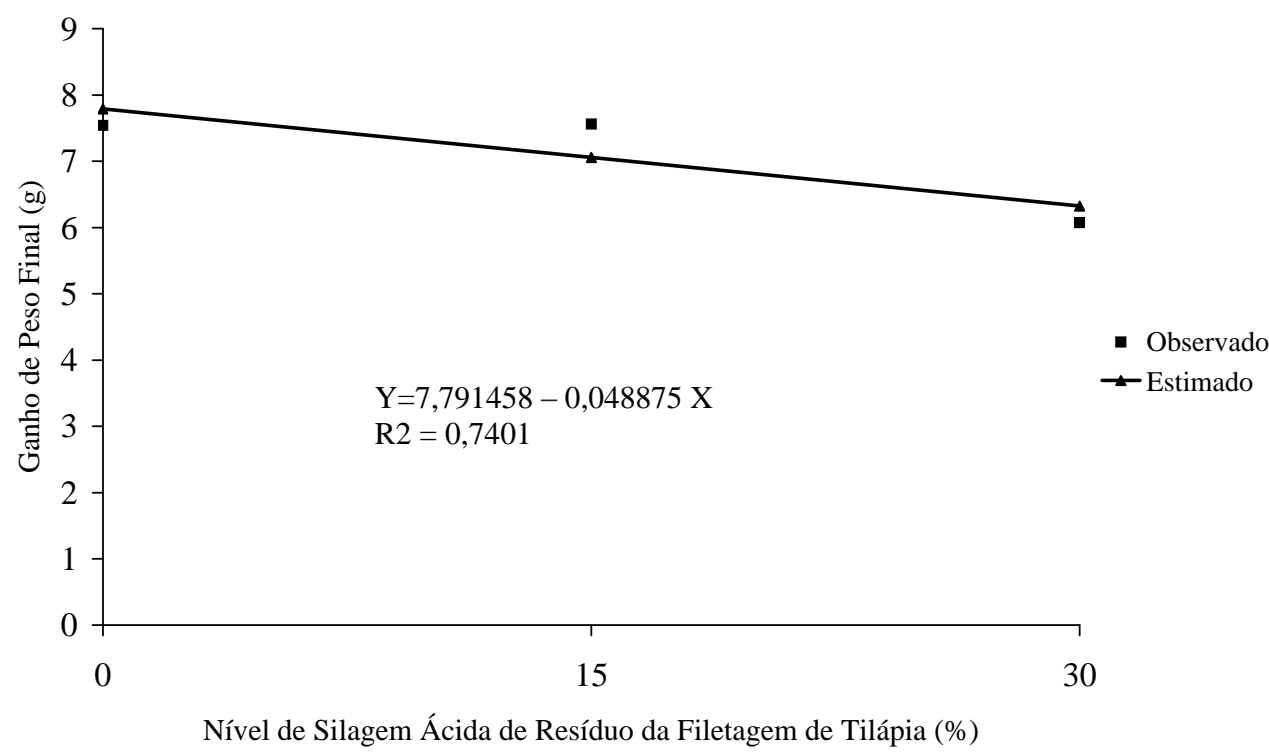

Figura 1 - Ganho de peso final (g) de girinos de rã-touro (Rana catesbeiana Shaw, 1802) submetidas a diferentes níveis de silagem ácida de resíduos da filetagem de tilápia na ração. 


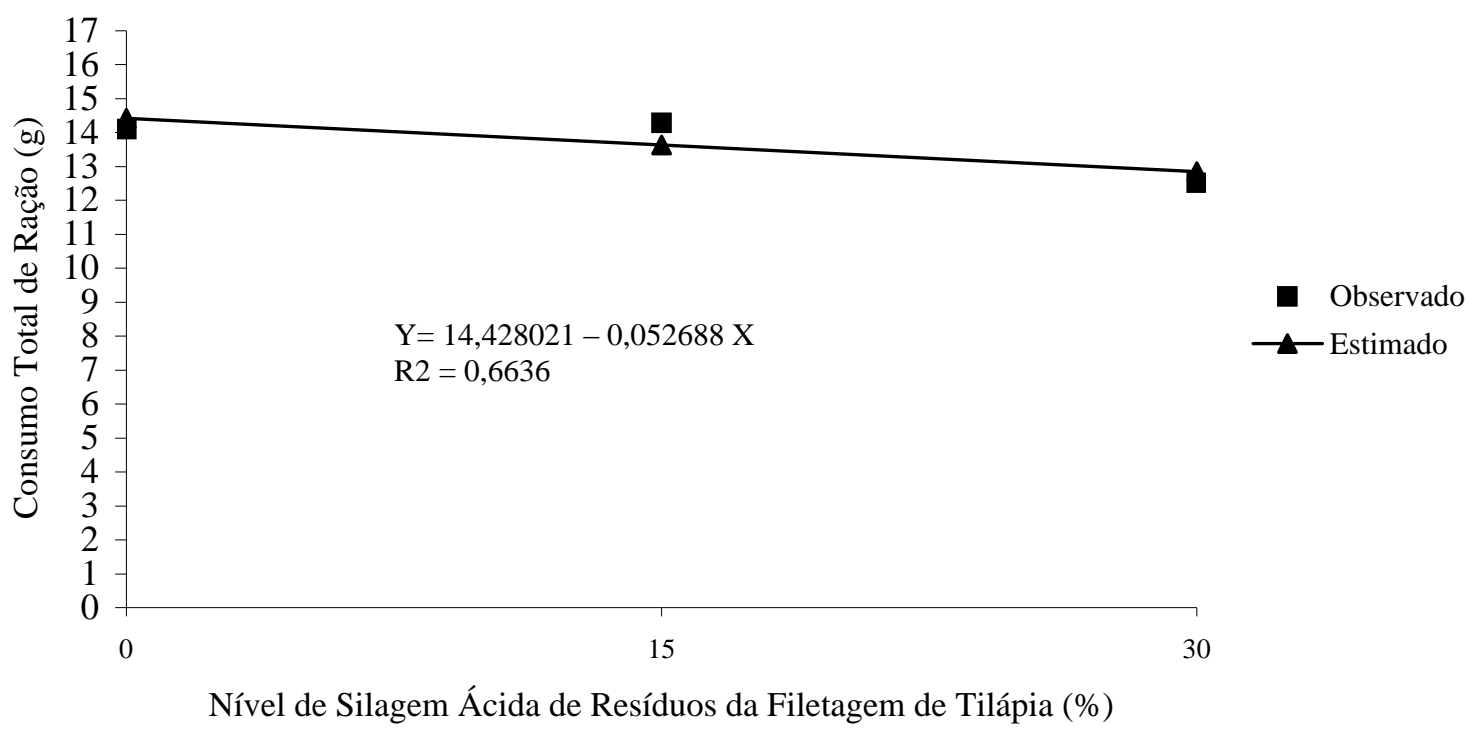

Figura 2 - Consumo total de ração de girinos de rã-touro (Rana catesbeiana Shaw, 1802) submetidas a diferentes níveis de silagem ácida de resíduos da filetagem de tilápia na ração.

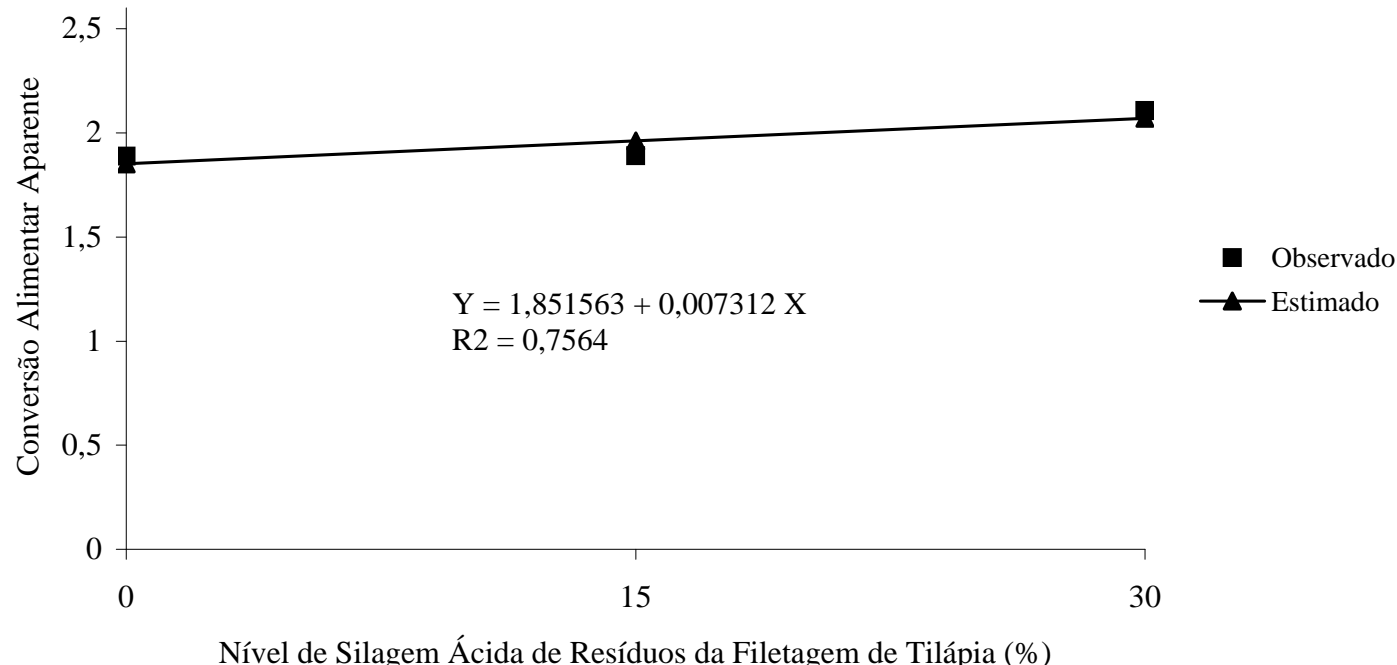

Figura 3 - Conversão alimentar aparente de girinos de rã-touro (Rana catesbeiana Shaw, 1802) submetidas a diferentes níveis de silagem ácida de resíduos da filetagem de tilápia na ração.

Nos níveis avaliados, houve uma diminuição linear $(\mathrm{P}<0,01)$ no ganho de peso final à medida que houve um aumento na substituição da farinha de peixe por silagem ácida de resíduo da filetagem de tilápia. Secco (2002), trabalhando com girinos, não observou diferença significativa no ganho de peso dos girinos ao incluir 50\% de silagem ácida de resíduos da filetagem de tilápia em substituição à farinha de peixe. Por outro lado, Fagbenro \& Jauncey (1995), trabalhando com bagre africano, observaram um menor ganho de peso quando estes recebiam rações contendo silagem de peixe.

O consumo final de ração também diminui linearmente $(\mathrm{P}<0,01)$ com o aumento dos níveis de 
substituição da farinha de peixe pela silagem ácida de resíduos da filetagem de tilápia. Este fato explica o menor ganho de peso apresentado pelos girinos de rã-touro ao receber os mesmos níveis crescentes da silagem, em substituição à farinha de peixe.

A conversão alimentar aparente, por ser uma relação entre o consumo total da ração e o ganho de peso final, piorou linearmente ao se fornecer níveis crescentes de silagem ácida de resíduos da filetagem de tilápia em substituição à farinha de peixe, divergindo dos resultados encontrados por Secco et al. (2002), que não encontraram diferença significativa no fornecimento de $50 \%$ de silagem ácida em substituição à farinha de peixe, quando comparado à ração com $100 \%$ de farinha de peixe. Fagberno \& Jauncey (1995) não encontraram também diferenças significativas na conversão alimentar dos bagres africanos que receberam dietas contendo silagem de peixe comparada a uma ração comercial.

Frente aos dados de digestibilidade anteriormente apresentados, pode-se inferir que, provavelmente, o perfil aminoacídico da silagem em estudo não é adequado às exigências dos girinos.

\section{CONCLUSÃO}

Os resultados indicam que a substituição da farinha de peixe por silagem ácida de resíduos da filetagem de tilápia resulta em pior desempenho dos girinos, apesar dos altos coeficientes de digestibilidade.

\section{REFERÊNCIAS BIBLIOGRÁFICAS}

ASSOCIATION OF OFFICIAL AGRICULTURE CHEMISTS. Official methods of analysis of the Association of Official Agriculture Chemists. Washington, 1990.

ALBINATI, R. C. B. Estudos biométricos e nutricionais com girinos de rã-touro (Rana catebeiana, Shaw, 1802). 1995. 103 f. Tese (Doutorado) - Universidade Federal de Viçosa, Viçosa, 1995.

BRAGA, L. G. T.; LIMA, S. L.; DONZELE, J. L. Valor nutritivo de alguns alimentos para rã-touro (Rana catesbeiana Shaw, 1802) na fase de recria. Revista Brasileira de Zootecnia, Viçosa, v. 27, n. 2, p. 203-209, 1998.

CASTRO, J. C.; LIMA, S. L.; DONZELE, J. L.; BRAGA, L. G. T. Energia metabolizável de alguns alimentos usados em rações de rãs. Revista Brasileira de Zootecnia, Viçosa, v. 27, n. 6, p. 1051-1056, 1998.
CHO, C. H. La energia en la nutrición de los peces. In: . Nutrición en cuicultura II. Madrid-España: J. Espinosa de los Monteros y U. Labarta, 1987. p. 197-237.

CHO, C. Y.; COWEY, C. B.; WATANABE, T. Finfish nutrition in Asia: methodological approaches to research and development. Otawa: IDRC, 1985. 154 p.

CISSE, A.; LUQUET, P.; ETCHIAN, A. Use of chemical or biological fish silage as feed for Chrysichthys nigrodigitatus (Bagridae). Aquatic Living Resources, Montrouge, v. 8, n. 4, p. 373-377, 1995.

ESPE, M.; SVEIER, H.; HOGOY, I. Nutrient absorption and growth of Atlantic salmon (Salmo salar salar L.) fed fish protein concentrate. Aquaculture, Amsterdam, v. 174, p. 119-137, 1999.

EUCLIDES, R. F. Manual de utilização do programa SAEG (Sistema para Análises Estatística e Genética). Viçosa: UFV, 1983.59 p.

FAGBENRO, O. A.; JAUNCEY, K. Growth and protein utilization by juvenile catfish (Clarias gariepinus) fed dry diets containing co-dried lactic-acid-fermented fish-silage and protein feedstuffs. Bioresource Technology, [S.1.], v. 51, p. 29-35, 1995.

FERREIRA, D. F. Análises estatísticas por meio do SISVAR para Windows versão 4.0. In: REUNIÃO ANUAL DE REGIÃO BRASILEIRA DA SOCIEDADE INTERNACIONAL DE BIOMETRIA, 45., 2000, São Carlos, SP. Anais... São Carlos: UFSCar, 2000. p. 255-258.

KIMURA, F. T.; MILLER, V. L. Improved determination of cromic oxid in cal feed and feces. Journal Agriculture Food Chemistry, Easton, v. 5, n. 2, p. 216, 1957.

LIMA, S. L.; AGOSTINHO, C. A. A tecnologia de criação de rãs. Viçosa: UFV, 1992. 168 p.

MUKHOPADHYAY, N.; RAY, A. K. The apparent total and nutrient digestibility of sal seed (Shorea rubusta) meal in rohu, Labeo rohita (Hamilton), fingerlings. Aquaculture Research, Amsterdam, v. 28, p. 683-689, 1997.

NATIONAL RESEARCH COUNCIL. Nutrient requeriments of warmwater, fishs and shellfishes: nutrient requeriments of domestic animals. Washington, DC, 1993. 114 p. 
RAMOS, O. V.; DORADO, M. del P.; CARO, E. O. Ensayo sobre la alimentacion de la cachama negra (colossoma macropomum) com pescado en acidos organico e inorganico (Fish silage). Boletin Cientifico INPA, [S.1.], v. 2, p. 46-61, 1994.

SECCO, E. M.; STÉFANI, M. V. D.; VIDOTTI, R. M. Substituição da farinha de peixe pela silagem de peixe na alimentação de Girinos de Rã-touro (Rana catesbeiana). Ciência Rural, Santa Maria, v. 32, n. 3, maio/jun. 2002.
VEIGA, N. Importância da alimentação e nutrição em ranicultura. In: MINI-SIMPÓSIO DO COLÉGIO BRASILEIRO E NUTRIÇÃO ANIMAL, 3., 1989, Botucatu. Anais... Botucatu: Unesp, 1989. p. 4569.

WINDSOR, M.; BARLOW, S. Introducion a los subproductos de pesqueria. Zaragoza: Acríbia, 1984. 204 p. 